\title{
REVIEW
}

\section{Bench-to-bedside review: Citrate for continuous renal replacement therapy, from science to practice}

\author{
Heleen M Oudemans-van Straaten 1,* and Marlies Ostermann²
}

\begin{abstract}
To prevent clotting in the extracorporeal circuit during continuous renal replacement therapy (CRRT) anticoagulation is required. Heparin is still the most commonly used anticoagulant. However, heparins increase the risk of bleeding, especially in critically ill patients. Evidence has accumulated that regional anticoagulation of the CRRT circuit with citrate is feasible and safe. Compared to heparin, citrate anticoagulation reduces the risk of bleeding and requirement for blood products, not only in patients with coagulopathy, but also in those without. Metabolic complications are largely prevented by the use of a strict protocol, comprehensive training and integrated citrate software. Recent studies indicate that citrate can even be used in patients with significant liver disease provided that monitoring is intensified and the dose is carefully adjusted. Since the citric acid cycle is oxygen dependent, patients at greatest risk of accumulation seem to be those with persistent lactic acidosis due to poor tissue perfusion. The use of citrate may also be associated with less inflammation due to hypocalcemia-induced suppression of intracellular signaling at the membrane and avoidance of heparin, which may have proinflammatory properties. Whether these beneficial effects increase patient survival needs to be confirmed. However, other benefits are the reason that citrate should become the first choice anticoagulant for CRRT provided that its safe use can be guaranteed.
\end{abstract}

*Correspondence: hmoudemans@gmail.com

'Department of Intensive Care Medicine, Onze Lieve Vrouwe Gasthuis, Oosterpark 9, 1091 AC Amsterdam, The Netherlands

Full list of author information is available at the end of the article

\section{Introduction}

Anticoagulation is required to prevent clotting in the extracorporeal circuit during continuous renal replacement therapy (CRRT). Heparin is still the most commonly used anticoagulant to maintain circuit patency, especially since it is effective, instantaneous in its anticoagulation and cheap. However, bleeding is the main side effect, especially in critically ill patients [1]. Furthermore, the use of heparin is hampered by complex interactions with acute phase proteins and cells and by the potential development of heparin-induced thrombocytopenia. Heparin can also inhibit the anti-inflammatory effects of antithrombin and trigger the release of inflammatory mediators from blood and endothelial cells. This can lead to an unpredictable dose-effect relationship and an uncontrollable and potentially deleterious interference with pro- and anti-inflammatory pathways [2]. Regional anticoagulation with citrate offers an attractive alternative, but is still not standard care. Although citrate is primarily used for extracorporeal anticoagulation, it also has an effect on acid-base balance, energy supply and membraneinduced inflammation, and indirectly on parathyroid hormone (PTH) secretion. The aim of this narrative review is to describe the complexity of citrate anticoagulation, to review the science underlying clinical decision-making and to summarize the clinical benefits of citrate.

\section{Mechanism of regional anticoagulation with citrate} Citrate acts by chelating calcium and therefore inhibits the clotting cascade at several levels. It provides regional anticoagulation, virtually restricted to the extracorporeal circuit. Citrate systems work on simple and shared modalities: a) pre-filter infusion of citrate, which chelates ionized calcium (ionCa ${ }^{2+}$; aiming for an ion $\mathrm{Ca}^{2+}$ concentration $<0.35 \mathrm{mmol} / \mathrm{L}$ ); b) a replacement infusion of calcium at the end of the extracorporeal circuit or via a separate venous access to correct for the calcium loss into filtrate or calcium-free dialysate; and c) preferable use of calcium-free dialysis or filtration fluids. Some authors report the use of calcium-containing solutions. However, when used in hemodialysis or pre-dilution 
hemofiltration, a higher citrate concentration in the filter (mmol citrate/L blood flow) is required to attain a similar degree of hypocalcemia in the circuit [3-8], and when administered for post-dilution in the venous chamber, the risk of local clotting is increased $[9,10]$.

Whereas citrate causes a dose-dependent decrease of ion $\mathrm{Ca}^{2+}$ concentration, the relationship between ion $\mathrm{Ca}^{2+}$ concentration and the degree of anticoagulation is more complex. Citrate has almost no anticoagulant effect when ionCa ${ }^{2+}$ levels remain $>0.50 \mathrm{mmol} / \mathrm{l}[11]$ or $>0.56 \mathrm{mmol} / \mathrm{L}$ [12]. However, clotting times steeply increase when ion $\mathrm{Ca}^{2+}$ levels decrease further. Below 0.25 [11] or $0.33 \mathrm{mmol} / \mathrm{L}$ [12] there is near total inhibition of coagulation.

Anticoagulation can be monitored by measuring postfilter ionCa ${ }^{2+}$ with adjustment of citrate dose according to the desired calcium target. Other protocols are less complex and use a fixed citrate dose proportional to blood flow targeting a citrate concentration in the filter of about $3 \mathrm{mmol} / \mathrm{L}[13,14]$.

Citrate is partially removed by filtration or dialysis. Its sieving coefficient is about one for both dialysis and hemofiltration [8]. The removed fraction varies between 0.20 and 0.50 depending on the relationship between blood and effluent flow and on CRRT modality. Citrate requirements are lower with dialysis because, to achieve similar effluent doses, dialysis is possible with lower blood flows. Furthermore, dialysis removes a higher fraction of the infused citrate due to the higher ratio of effluent to blood flow [15]. In case of hemofiltration, removal approaches filtration fraction. The remaining citrate enters the patient where coagulation is restored because a) the circuit blood is diluted in the patient's circulation and b) citrate is rapidly metabolized in the mitochondrial citric acid cycle in liver, kidney and muscle, liberating the bound calcium. As a result, citrate has anticoagulant properties only within the circuit and not in the patient.

\section{Citrate solutions and acid base effects}

There are numerous citrate solutions for daily practice. The choice depends on local availability, preferences regarding CRRT modality (pre- or post-dilution, diffusion versus convection), legislation and available software. None of the solutions have proven clinical superiority, but the individual type of solution can have different metabolic consequences [13,14].

In principle, citrate is infused either as a separate trisodium citrate (TSC) [9,16-20], acid-citrate-dextrose (ACD) solution [4-7,21,22], or as a component of an isotonic citrate in saline with [23] or without citric acid [18] or of a balanced pre-dilution replacement fluid [24-29] (Table 1). Although citrate is primarily used for extracorporeal anticoagulation, it has profound effects on acid-base balance as well. Anticoagulant and acid-base effects are not directly related. The degree of anticoagulation depends on citrate dose and hypocalcemia (see above), while the effect on acid base state depends on metabolism of citrate and the 'apparent strong ion difference' of the solution (SIDa $=\left[\mathrm{Na}^{+}+\mathrm{K}^{+}+\mathrm{Ca}^{2+}+\mathrm{Mg}^{2+}\right]-$ $\left[\mathrm{Cl}^{-}+\right.$citrate $\left.\left.^{3-}\right]\right)$ [30], that is, the type of cations opposing the citrate anion. For example, only two thirds of the cations in ACD solution are strong ions (that is, $\mathrm{Na}^{+}$). The buffer strength of $\mathrm{ACD}$ is therefore lower than that of the pure TSC solution. Within the body, citrate is rapidly metabolized and the effective SID (SIDe) of the solution is $\left[\mathrm{Na}^{+}+\mathrm{K}^{+}+\mathrm{Ca}^{2+}+\mathrm{Mg}^{2+}\right]-[\mathrm{Cl}]$. Thus, the alkalizing effect of the citrate solution depends on the metabolism of citrate. In clinical practice, the citrate dose is primarily titrated according to its anticoagulant effects (hypocalcemia). Therefore, the buffer strength can be best compared between solutions when expressing SIDe per mmol citrate (Table 1).

The accompanying dialysis or replacement solutions should compensate for the sodium load and buffer strength of the citrate solution used and for the loss of calcium and magnesium. For this reason, the composition of the dialysis or replacement fluids and their metabolic side effects differ in the various citrate anticoagulation protocols [13,14]. Depending on the modality used, metabolic acidosis can be corrected by increasing citrate dose, effluent dose (removal of metabolic acids) or bicarbonate replacement, and metabolic alkalosis vice versa. It should be noted that when using the isotonic balanced citrate-containing pre-dilution replacement solution, anticoagulant dose and CRRT dose (effluent flow) cannot be adjusted separately $[29,31]$. When using a low-bicarbonate dialysis solution, acidosis is corrected by increasing citrate dose and decreasing dialysis flow [19]. To date, no studies have compared the different modalities on clinical endpoints.

\section{Clinical benefits of citrate}

Clinical benefits of citrate are primarily related to less bleeding, a better circuit survival and lower requirement for blood products. A recent meta-analysis, including 6 randomized controlled trials (RCTs) with a total of 488 patients and data on 658 circuits, with a focus on safety and efficacy of citrate anticoagulation, found a longer circuit survival time and a reduced risk of bleeding [32]. Control anticoagulation used in the six different studies was unfractionated heparin $[10,17,20]$, low molecular weight heparin [9] or regional heparinization [33]. Metabolic derangements were similar to control anticoagulation and could be controlled easily. Notably, in the largest clinical trial, citrate anticoagulation was better tolerated than heparin [9]. It should also be noted that patients with an increased bleeding risk - that is, those who are likely to benefit most from citrate 
Table 1. Composition and buffer strength of the different citrate solutions

\begin{tabular}{|c|c|c|c|c|c|c|}
\hline & \multicolumn{3}{|c|}{ Separate citrate solutions } & \multicolumn{3}{|c|}{ Citrate-buffered pre-dilution replacement fluid } \\
\hline & TSC & $\mathrm{TSC}+\mathrm{Ca}$ & ACD-A & $\mathrm{TSC}+\mathrm{Ca}+\mathrm{NaCl}$ & $\mathrm{TSC}+\mathrm{NaCl}$ & $\begin{array}{c}\text { Citrate in } \\
\text { balanced fluid }\end{array}$ \\
\hline $\mathrm{Na}^{+}, \mathrm{mmol} / \mathrm{L}$ & $210-3,000$ & 1,352 & 224 & 136 & 140 & $140-159$ \\
\hline $\mathrm{H}^{+}, \mathrm{mmol} / \mathrm{L}$ (\% of cations) & None & 148 & $115(33)$ & 6 & None & None \\
\hline Citrate $^{3-}, \mathrm{mmol} / \mathrm{L}$ & $68-1,000$ & $450(+50)^{\mathrm{a}}$ & 113 & $10(+2)^{b}$ & 18 or 23 & $13.3-20$ \\
\hline Glucose, $\mathrm{mmol} / \mathrm{L}$ & None & None & 139 & None & None & \pm 5 \\
\hline $\mathrm{K}^{+}, \mathrm{mmol} / \mathrm{L}$ & None & None & None & None & None & $0-3$ \\
\hline $\mathrm{Mg}^{2+}, \mathrm{mmol} / \mathrm{L}$ & None & None & None & None & None & $0-0.75$ \\
\hline $\mathrm{Cl}^{2-}, \mathrm{mmol} / \mathrm{L}$ & None & None & None & 106 & 86 or 81 & $99-108$ \\
\hline $\mathrm{SIDe}^{\mathrm{c}}, \mathrm{mmol} / \mathrm{L}$ & 3,000 & 1,352 & 224 & 30 & 54 & $33-54$ \\
\hline SIDe per mmol citrate & 3 & 2.7 & 2.0 & 3 & 3 & $2.25-3$ \\
\hline
\end{tabular}

aThe 50 citrate ions are from citric acid. ${ }^{b}$ The two citrate ions are from citric acid. ${ }^{c}$ SIDe: effective strong ion difference as calculated after metabolism of citrate: $\left(\mathrm{Na}^{+}+\mathrm{K}^{+}+\mathrm{Ca}^{2+}+\mathrm{Mg}^{2+}\right)-(\mathrm{Cl})$. ACD-A, acid citrate dextrose; $\mathrm{Ca}$, citric acid; $\mathrm{NaCl}$, saline; $\mathrm{SIDe}$, effective strong ion difference; TSC, trisodium citrate.

anticoagulation - were not included in the randomized studies. Similarly, patients with liver failure were excluded and therefore results do not apply to this population either. In contrast to the above-mentioned meta-analysis, a repeat meta-analysis including the same six RCTs concluded that the efficacy of citrate and heparin for CRRT was similar, but citrate decreased the risk of bleeding with no significant increase in the incidence of metabolic alkalosis [34]. The main reason for the discrepant results related to circuit life was the different way the authors handled the study by Betjes and colleagues [10], which did not report interquartile ranges of circuit survival. Zhang and colleagues [32] estimated the survival times by scaling the Kaplan-Meier curve. In contrast, Wu and colleagues [34] did not include this study in their circuit survival analysis.

Most of the studies on citrate anticoagulation are too small to evaluate patient outcome [13]. However, the largest (single center) trial (performed by one of the authors), including 200 critically ill patients, unexpectedly showed a $15 \%$ absolute increase in 3-month survival using an intention to treat analysis [9]. Among the higher proportion of surviving patients, there was a trend towards better renal recovery with more patients free from chronic dialysis in the citrate group $(P=0.08)$. Of note, the benefit of citrate on survival could not be fully explained by less bleeding. Although citrate did not perform worse in any post hoc subgroup, it appeared particularly beneficial in surgical patients, younger patients, patients with sepsis and in patients with more organ failure, suggesting either a protective role of citrate or harmful effects of heparin during inflammation. A subsequent multi-centre RCT did not confirm the survival benefit with citrate [35]. However, this trial was smaller, included a younger patient population with less severe organ failure, used a different citrate protocol, and had a short follow-up period and a high proportion of drop outs.

\section{Bioenergetic consequences}

Potential sources of CRRT-derived energy consist of citrate, glucose (in ACD) and lactate. Their respective caloric equivalents are $2.48 \mathrm{~kJ}(0.59 \mathrm{kcal}), 3.06 \mathrm{~kJ}$ $(0.73 \mathrm{kcal})$ and $1.37 \mathrm{~kJ}(0.33 \mathrm{kcal})$ per millimole. Net energetic gain depends on the dose infused and the amount removed by CRRT. The dose of citrate infused during hemodialysis is lower compared to hemofiltration, not because of a better clearance with dialysis (sieving coefficients approach 1 for both), but because hemodialysis is feasible with lower blood flow rates [15]. Table 2 shows an estimate of the daily energy delivery when using different modalities and citrate solutions for CRRT at a dose of $2 \mathrm{~L} / \mathrm{h}$. During continuous venovenous hemodialysis (CVVHD), energy delivery is lowest with TSC as citrate source and during pre-dilution CVVH using an isotonic citrate-containing replacement fluid. ACD contains $139 \mathrm{mmol}$ glucose/L. When used as citrate source, it provides about $350 \mathrm{kcal} /$ day $(1,466 \mathrm{~kJ})$ during CVVHD and about $500 \mathrm{kcal} /$ day $(1,294 \mathrm{~kJ})$ during postdilution CVVH. Lactate-containing replacement fluids together with citrate [6,7] during CRRT at $2 \mathrm{~L} / \mathrm{h}$ add about $550 \mathrm{kcal}(2,303 \mathrm{~kJ})$ to daily energy delivery (Table 2$)$.

The question is whether this energy delivery is beneficial or harmful. First, some energy provision may be useful since it compensates for the losses of amino acids and small peptides during CRRT. Second, both citrate and lactate may be easy fuel under stress [36-40]. Neither rely on insulin to enter the cell and citrate can replenish the Krebs cycle when intermediates are scarce [41]. Substrate availability is a crucial regulator of the Krebs cycle. Citrate enters cells directly providing intermediates to the cycle. Thereby, citrate can restore 
Table 2. Globally estimated total energy delivery for three common CRRT settings, postdilution CVVH and CVVHD using different citrate solutions with or without lactate replacement fluids, and predilution CVVH at a CRRT dose of 2 L/h

\begin{tabular}{|c|c|c|c|c|c|c|}
\hline & & \multicolumn{2}{|c|}{ TSC solution } & \multicolumn{2}{|c|}{ ACD solution } & \multirow{2}{*}{ 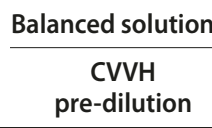 } \\
\hline & & $\begin{array}{c}\text { CVVH } \\
\text { post-dilution }\end{array}$ & CVVHD & $\begin{array}{c}\mathrm{CVVH} \\
\text { post-dilution }\end{array}$ & CVVHD & \\
\hline \multicolumn{7}{|l|}{ CRRT settings } \\
\hline QB & $\mathrm{ml} /$ minute & 150 & 100 & 150 & 100 & 150 \\
\hline Citrate target & $\mathrm{mmol} / \mathrm{LQB}$ & 4 & 4 & 4 & 4 & 3.7 \\
\hline Citrate dose & $\mathrm{mmol} / \mathrm{h}$ & 36 & 24 & 36 & 24 & 33 \\
\hline CRRT dose & $\mathrm{ml} / \mathrm{h}$ & 2,000 & 2,000 & 2,000 & 2,000 & $2,500^{\mathrm{a}}$ \\
\hline Removal & Fraction & 0.22 & 0.33 & 0.22 & 0.33 & 0 \\
\hline \multicolumn{7}{|l|}{ Delivery to the patient } \\
\hline \multirow[t]{3}{*}{ Citrate } & $\mathrm{mmol} / \mathrm{h}$ & 28 & 16 & 28 & 16.08 & 13 \\
\hline & $\mathrm{kcal} / \mathrm{h}$ & 14 & 8 & 14 & 8 & 7 \\
\hline & $\mathrm{kJ} / \mathrm{h}$ & 69 & 40 & 69 & 40 & 33 \\
\hline \multirow[t]{3}{*}{ Glucose } & $\mathrm{mmol} / \mathrm{h}$ & & & 34 & 20 & \\
\hline & $\mathrm{kcal} / \mathrm{h}$ & & & 25 & 14 & \\
\hline & $\mathrm{kJ} / \mathrm{h}$ & & & 105 & 61 & \\
\hline \multirow[t]{3}{*}{ Lactate } & $\mathrm{mmol} / \mathrm{h}$ & 70 & 70 & 70 & 70 & \\
\hline & $\mathrm{kcal} / \mathrm{h}$ & 23 & 23 & 23 & 23 & \\
\hline & $\mathrm{kJ} / \mathrm{h}$ & 96 & 96 & 96 & 96 & \\
\hline \multirow[t]{2}{*}{ Total energy excluding lactate } & $\mathrm{kcal} / 24 \mathrm{~h}$ & 343 & 196 & 946 & 543 & 163 \\
\hline & $\mathrm{kJ} / 24 \mathrm{~h}$ & 1,667 & 952 & 4,196 & 2,410 & 4,852 \\
\hline \multirow[t]{2}{*}{ Total energy including lactate } & $\mathrm{kcal} / 24 \mathrm{~h}$ & 897 & 750 & 1,501 & 1,098 & \\
\hline & $\mathrm{kJ} / 24 \mathrm{~h}$ & 3,968 & 3,254 & 6,497 & 4,711 & \\
\hline
\end{tabular}

aPredilution dose is corrected for loss due to dilution. Caloric equivalents per millimole: citrate $2.48 \mathrm{~kJ}(0.59 \mathrm{kcal})$, glucose $3.06 \mathrm{~kJ}(0.73 \mathrm{kcal})$ and lactate $1.37 \mathrm{~kJ}$ $(0.33 \mathrm{kcal})$. ACD, acid citrate dextrose; CRRT, continuous renal replacement therapy; $C V V H$, continuous venovenous hemofiltration; CVVHD continuous venovenous hemodialysis; QB, blood flow; TSC, trisodium citrate.

mitochondrial ATP and redox state under conditions of reperfusion after hypoxia [42] or limited substrate availability [43]. Lactate enters the mitochondria, where it is converted to pyruvate generating ATP, or enters the liver for gluconeogenesis. Third, glycolysis requires an initial investment of ATP before more ATP is produced [44]. Therefore, when energy stores are depleted, citrate and lactate may be preferable over glucose [36-38]. On the other hand, using ACD as citrate source means that 90 to $150 \mathrm{~g}$ of glucose is infused per day, because the solution provides $1.23 \mathrm{mmol}$ glucose for each millimole of citrate. This degree of energy delivery may pose an unnecessary strain, especially when using ACD in combination with lactate-buffered replacement fluids [7]. It is important to be aware of the metabolic consequences of any type of fluid used and to adjust nutritional intake when necessary [45].

\section{Citrate and inflammation}

Hypocalcemia and reduction of inflammation

Activation of neutrophils and platelets and the subsequent release of mediators from intracellular granules are regulated by cytosolic $\mathrm{Ca}^{2+}$, which acts as an intracellular messenger [46-49]. Cytosolic $\mathrm{Ca}^{2+}$ is maintained through mobilization from intracellular stores and an influx of extracellular $\mathrm{Ca}^{2+}$ via plasma membrane channels. Therefore, citrate-induced changes of the extracellular calcium concentration may have a direct effect on intracellular $\mathrm{Ca}^{2+}$ signaling. Hypocalcemia in the filter not only downregulates membrane-induced inflammation [50-53], but seems to reduce systemic inflammation as well $[54,55]$.

Several pro-inflammatory actions of neutrophils are calcium-dependent. Among them are superoxide generation, adhesion, degranulation, phospholipase-A2 activation and interleukin-8 synthesis [46]. We stimulated isolated leukocytes under different extracellular calcium conditions with and without citrate, and found that inhibition of the cytosolic $\mathrm{Ca}^{2+}$ increase after stimulation with N-formyl-L-methionyl-L-leucyl-Lphenylalanine (fMLP) depends on the degree of extracellular hypocalcemia and not on the presence of citrate. Typical results of a single experiment are presented in Figure 1 . The effects of citrate on complement activation, especially seen when using the old unsubstituted 


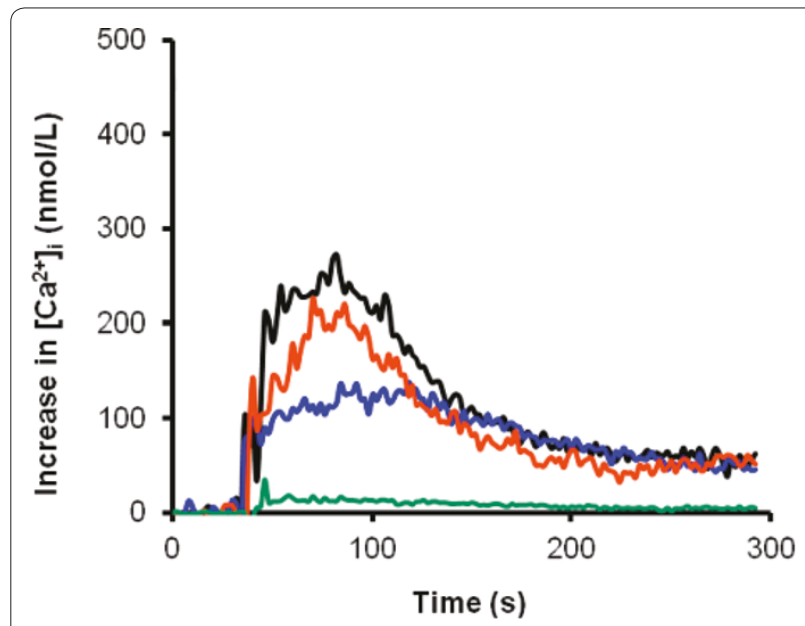

Figure 1. Comparison of the intracellular calcium increase $\left(\left[\mathrm{Ca}^{2+}\right] \mathrm{i}\right)$ in isolated leukocytes after in vitro stimulation with $\mathrm{N}$-formyl-L-methionyl-L-leucyl-L-phenylalanine (fMLP) at different extracellular calcium concentrations with and without citrate. Green, $1 \mathrm{mmol} / / \mathrm{EGTA}$, creating $\left[\mathrm{ecCa}^{2+}\right]<0.025 \mathrm{mmol} / \mathrm{L}$;

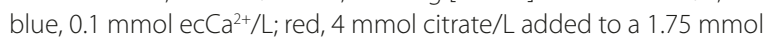
ecCa ${ }^{2+} / \mathrm{L}$ solution; black, $1.75 \mathrm{mmol}$ ecCa ${ }^{2+} / \mathrm{L}$. [Heemskerk JW, Feijge MA, Oudemans-van Straaten HM]

cuprophane membranes, are not uniform; some studies found no effect $[47,52,55]$, whereas others reported suppression of the complement cascade [50]. Complement activation and associated neutropenia seem to be mediated by a different membrane receptor, not related to degranulation.

\section{Avoidance of the non-anticoagulant effects of heparins on inflammation}

In addition to their anticoagulant effects, heparins have both pro- and anti-inflammatory effects elicited by their binding to numerous proteins and cells. The balance of these effects likely depends on the site of heparin binding, on heparin dose and on the presence, type and severity of sepsis [56-58] and may be beneficial [59-61], neutral [62], but totally unpredictable and potentially deleterious [58,63-67]. Anti-inflammatory effects may be due to inhibition of the formation of thrombin. In addition, heparins may attenuate neutrophil-induced endothelial damage by inhibiting leukocyte adherence to the endothelial cells as well as mast-cell activation by prevention of intracellular calcium release [56]. Pro-inflammatory effects may primarily be due to the binding and inhibition of endothelial antithrombin, thereby preventing local prostacyclin formation (summarized in [2]) and hampering the microcirculation $[66,67]$. Furthermore, during sepsis, heparin may contribute to the inactivation of antithrombin by elastase on vascular surfaces where neutrophils are sequestered [68]. Second, heparin can mobilize inflammatory mediators, such as myeloperoxidase, lactoferrin, elastase and platelet factor-4, not only from circulating neutrophils, platelets and cells adhered to and activated by the dialysis membrane, but also from heparan sulfate like substances on the endothelial surface $[64,65]$. Third, heparin binds to lipopolysaccharidebinding protein, and this process facilitates the transfer of lipopolysaccharide to the CD-14 receptor and augments endotoxin-induced activation of monocytes [58,67]. Finally, heparin avidly binds to discrete domains released from the nucleus onto the membrane of apoptotic or necrotic cells. These heparin-binding sites on apoptotic cells signal phagocytotic clearance and heparin may thus actually delay such clearance [63]. Therefore, by its binding to numerous proteins and cells, heparin induces unpredictable effects on many body functions and some of these may be harmful, especially during inflammation.

\section{Risks and limitations of citrate} Intoxication

The main risk of citrate anticoagulation is the unintended infusion of large amounts of citrate into the patient's circulation, which can lead to severe hypocalcemia, hypotension due to decreased myocardial contractility and vascular tone, and eventually cardiac arrest. This potentially severe adverse event can be instantaneously counteracted by calcium infusion. Unintended continued citrate infusion during the change of bags is usually not associated with clinical side effects, mainly because this amount is relatively low. However, the nursing staff should be aware of this potential risk. Fortunately, integrated software takes care of discontinuation of the citrate pump when bags are changed.

\section{Accumulation}

The main limitation of citrate anticoagulation is accumulation as a result of reduced mitochondrial citrate metabolism. Reduced metabolism is seen in patients with liver failure due to decompensated chronic liver disease and also in those with ischemic hepatitis and poor muscle perfusion as seen in prolonged cardiogenic shock. The citrate molecule itself is not toxic, but the symptoms of citrate accumulation are due to secondary hypocalcemia and acidosis. Monitoring of the patient's $\mathrm{Ca}^{2+}$ is therefore crucial. Ionized hypocalcemia is the most sensitive indicator of citrate accumulation [69]. While decreasing $\mathrm{Ca}^{2+}$, citrate accumulation concomitantly increases total calcium concentration, due to an increase in citratebound calcium as well as calcium supplementation in response to ionized hypocalcemia. The total to ionized calcium ratio, therefore, is a useful marker to detect citrate accumulation $[3,69,70]$ and seems the most specific [69]. A rise in total to ionized calcium ratio $>2.25$ should trigger the clinician to consider citrate accumulation. A recent prospective observational study in 208 critically ill 
medical patients receiving CRRT with regional citrate anticoagulation for acute kidney injury found that a ratio $\geq 2.4$ independently predicted a 33.5 -fold increase in 28-day mortality [71]. Failure to metabolize citrate therefore seems to indicate a high risk of dying. Citrate accumulation due to metabolic failure can lead to metabolic acidosis. However, measurement of the anion gap is not helpful in this setting, mainly because citrate accumulation due to metabolic failure tends to occur in situations where lactic acid accumulates too, that is, in the context of advanced liver disease or tissue hypoxia. In contrast, increased citrate infusion in patients with adequate metabolism (that is, in the context of inadvertent protocol error or after polytransfusion) can lead to metabolic alkalosis.

Management of citrate accumulation includes a) decreasing both citrate flow and blood flow if feasible, b) increasing citrate clearance (effluent flow), c) reducing or discontinuing citrate flow at the cost of anticoagulant activity (when citrate is part of the pre-dilution replacement, reduction of citrate dose is not an option, because the dose of anticoagulation and CRRT are coupled, and citrate should be replaced by bicarbonate with or without heparin), d) administration of intravenous calcium to correct hypocalcemia, and e) titrated replacement of bicarbonate to correct acidosis.

\section{Other electrolyte disturbances}

Systemic hypocalcemia during citrate anticoagulation may also be due to insufficient replacement - for example, when calcium replacement is lower than calcium loss. In that case, both total and ionized calcium decrease. The risk of calcium loss across the membrane is particularly high when calcium-free dialysate or replacement fluids are used. Although it may be rational to replace the lost amount of calcium, calcium replacement dose is generally adjusted according to actual systemic $\mathrm{Ca}^{2+}$ concentrations, which additionally reflect trans-cellular shifts, such as the influx of extracellular $\mathrm{Ca}^{2+}$ upon inflammatory stimuli $[46,48]$. Furthermore, the optimal ionCa ${ }^{2+}$ concentration during critical illness is not known. Critically ill patients often have low ionCa ${ }^{2+}$ concentrations [72] and supplementation of calcium might be harmful [73]. An alternative target for calcium replacement might be normalization of the PTH concentration. Citrate also binds to magnesium and this may cause hypomagnesemia due to increased magnesium loss. The use of highly concentrated trisodium citrate solutions may lead to hypernatremia if the sodium content of the replacement solutions is not proportionally reduced.

\section{Citrate in liver failure}

The metabolism of citrate is diminished in patients with liver failure [74,75]. Unfortunately, citrate clearance cannot be reliably predicted from standard liver function tests. However, adjustment of dose and intensified monitoring of ionized calcium levels seem to allow the safe use of citrate in patients with decompensated cirrhosis. Two recent studies showed the feasibility of citrate anticoagulation in patients with liver failure receiving treatment with a molecular absorbent recirculating system (MARS) [76,77]. In the observational study, the median citrate infusion rate was $3.1 \mathrm{mmol} / \mathrm{L}$ blood flow and median duration of treatment was $20 \mathrm{~h}$ [76]. Although the total to ionized calcium ratio increased significantly, treatment was well tolerated. The second study was a randomized cross-over study comparing citrate anticoagulation with no anticoagulation. Out of 27 sessions, 4 had to be terminated prematurely but all 4 were in the no anticoagulation group [77]. The use of citrate was associated with a lower ionized calcium concentration, albeit without adverse events. It should be noted that the MARS treatments are intermittent. However, in a large prospective observational study including 133 patients treated with citrate-based continuous venovenous hemodialysis for 72 hours, citrate anticoagulation was well tolerated in 86 patients with liver dysfunction as defined by a bilirubin $>2 \mathrm{mg} / \mathrm{dl}$ [78]. Only $2 \%$ of patients developed an increased total to ionized calcium ratio $(\geq 2.5)$.

\section{Citrate in shock with lactate acidosis}

Citrate metabolism occurs primarily in liver and muscle. A high lactate concentration in patients with shock at the start of CRRT should raise awareness of the risk of citrate accumulation, because this may indicate mitochondrial dysfunction. Nevertheless, clinical practice shows that a considerable proportion of patients with shock do tolerate citrate anticoagulation, especially those with septic shock and high lactate levels if circulation improves. In the randomized controlled trial by one of the authors, only one patient developed signs of citrate accumulation [9]. However, citrate is likely to accumulate in patients with persistent severe heart failure, ischemic hepatitis and poor muscle perfusion, because the Krebs cycle only operates under aerobic conditions. In these cases, intensified monitoring of the total to ionized calcium ratio and acid base balance is advised (2-hourly at start), and citrate infusion should be reduced or discontinued when calcium ratio increases above 2.25 to 2.5 .

\section{Effects on bone metabolism}

Systemic hypocalcemia is a potent stimulus for PTH secretion. In normal subjects, a decrease in serum ionized calcium of as little as $0.025 \mathrm{mmol} / \mathrm{L}$ leads to release of preformed PTH within minutes, followed by an increased production of biologically active PTH. The 
immediate effect of PTH is to mobilize calcium from skeletal stores. In patients with normal kidney function, PTH also increases tubular calcium reabsorption and stimulates the conversion of 25-hydroxyvitamin D3 to 1.25-dihydroxyvitamin D3. In critically ill patients with acute kidney injury, the renal effects of PTH may be negligible, but concern about the potential harmful effects on bone metabolism has been expressed [79]. Three studies in critically ill patients with acute kidney injury reported a negative calcium balance and significant rise in intact PTH levels during citrate-based CRRT when aiming for systemic ionized calcium levels between 0.8 and $1.1 \mathrm{mmol} / \mathrm{L}$ [79-81]. The exact significance of PTH secretion during critical illness remains uncertain but severe bone reabsorption has been described during prolonged citrate-based CRRT. Adequate calcium replacement may be crucial for preventing bone loss.

\section{Strategies to increase the safety of citrate}

The full advantage of citrate can only be realized if its risks are well appreciated and controlled. Safe introduction of citrate starts with the choice of a well-designed and flexible protocol with proven efficacy, adjusted to the preferences for CRRT modality and dose, and availability of fluids and devices. Strict adherence to the protocol and its algorithms can prevent metabolic derangement. Safe implementation of citrate requires focused training of all staff involved, the availability of ionized calcium measurement $24 \mathrm{~h}$ a day and attention to detail. The risk of citrate intoxication can be avoided by using CRRT machines with integrated software that interrupt citrate infusion when the blood pump stops and also by preventing the unintended mix-up of citrate bags and crystalloid infusion bags by markedly different labeling. Intensified monitoring of ionized calcium is needed in patients with risk of accumulation. Patient safety can be improved by 'pop-up' alerts in the patient data management system, continuous monitoring of citrate and ionized calcium concentrations, and computerized algorithms predicting systemic and post-filter total or ionized calcium concentrations [82-84].

\section{Conclusion}

Evidence is accumulating that regional anticoagulation of the CRRT circuit with citrate is feasible and safe in critically ill patients. Compared to heparin, citrate anticoagulation reduces the risk of bleeding and associated blood transfusion, not only in patients with an increased risk of bleeding but also in those without. Metabolic complications depend on the type of fluids used and are largely prevented by the use of a strict protocol, training and integrated citrate software. Recent studies indicate that citrate can even be used in patients with (acute-onchronic) liver failure when monitoring is intensified and dose is carefully adjusted. Patients at greatest risk of accumulation are those with persistent poor tissue perfusion and lactic acidosis, since citrate metabolism is oxygen dependent. The use of citrate may additionally be associated with less inflammation due to hypocalcemia at the membrane and also by avoiding the therapeutic use of heparin. Whether these beneficial effects increase patient survival needs to be confirmed. However, its other benefits are reason enough [85] to make citrate the first choice anticoagulant for CRRT provided that its safe use can be guaranteed.

\section{Abbreviations}

$A C D$, acid-citrate-dextrose; CRRT, continuous renal replacement therapy; $\mathrm{CVVH}$, continuous venovenous hemofiltration; CVVHD, continuous venovenous hemodialysis; MARS, molecular absorbent recirculating system; PTH, parathyroid hormone; RCT, randomized controlled trial; SID, strong ion difference; TSC, trisodium citrate.

\section{Competing interests}

None of the authors has a financial or non-financial competing interest.

\section{Author details}

'Department of Intensive Care Medicine, Onze Lieve Vrouwe Gasthuis, Oosterpark 9, 1091 AC Amsterdam, The Netherlands. 'King's College London, Guy's and St Thomas' Hospital, Department of Critical Care and Nephrology, London SE1 7EH, UK.

Published: 7 December 2012

\section{References}

1. van de Wetering J, Westendorp RG, van der Hoeven JG, Stolk B, Feuth JD, Chang PC: Heparin use in continuous renal replacement procedures: the struggle between filter coagulation and patient hemorrhage. J Am SOC Nephrol 1996, 7:145-150.

2. Oudemans-Van Straaten HM, Kellum JA, Bellomo R: Clinical review: anticoagulation for continuous renal replacement therapy - heparin or citrate? Crit Care 2011, 15:202.

3. Meier-Kriesche HU, Gitomer J, Finkel K, DuBose T: Increased total to ionized calcium ratio during continuous venovenous hemodialysis with regional citrate anticoagulation. Crit Care Med 2001, 29:748-752.

4. Mitchell A, Daul AE, Beiderlinden M, Schafers RF, Heemann U, Kribben A, Peters J, Philipp T, Wenzel RR: A new system for regional citrate anticoagulation in continuous venovenous hemodialysis (CVVHD). Clin Nephrol 2003, 59:106-114.

5. Cointault O, Kamar N, Bories P, Lavayssiere L, Angles O, Rostaing L, Genestal $M$, Durand D: Regional citrate anticoagulation in continuous venovenous haemodiafiltration using commercial solutions. Nephrol Dial Transplant 2004, 19:171-178.

6. Gupta M, Wadhwa NK, Bukovsky R: Regional citrate anticoagulation for continuous venovenous hemodiafiltration using calcium-containing dialysate. Am J Kidney Dis 2004, 43:67-73.

7. Balik M, Zakharchenko M, Otahal M, Hruby J, Polak F, Rusinova K, Stach Z, Vavrova J, Jabor A: Quantification of systemic delivery of substrates for intermediate metabolism during citrate anticoagulation of continuous renal replacement therapy. Blood Purif 2012, 33:80-87.

8. Chadha V, Garg U, Warady BA, Alon US: Citrate clearance in children receiving continuous venovenous renal replacement therapy. Pediatr Nephrol 2002, 17:819-824.

9. Oudemans-Van Straaten HM, Bosman RJ, Koopmans M, van der Voort PH, Wester JP, van der Spoel Jl, Dijksman LM, Zandstra DF: Citrate anticoagulation for continuous venovenous hemofiltration. Crit Care Med 2009, 37:545-552.

10. Betjes MG, van Oosterom D, van Agteren M, van de Wetering J: Regional citrate versus heparin anticoagulation during venovenous hemofiltration in patients at low risk for bleeding: similar hemofilter survival but significantly less bleeding. J Nephrol 2007, 20:602-608.

11. Calatzis A, Toepfer M, Schramm W, Spannagl M, Schiff H: Citrate 
anticoagulation for extracorporeal circuits: effects on whole blood coagulation activation and clot formation. Nephron 2001, 89:233-236

12. James MF, Roche AM: Dose-response relationship between plasma ionized calcium concentration and thrombelastography. J Cardiothorac Vasc Anesth 2004, 18:581-586.

13. Oudemans-Van Straaten HM, Wester JP, de Pont AC, Schetz MR: Anticoagulation strategies in continuous renal replacement therapy: can the choice be evidence based? Intensive Care Med 2006, 32:188-202.

14. Joannidis M, Oudemans-Van Straaten HM: Clinical review: Patency of the circuit in continuous renal replacement therapy. Crit Care 2007, 11:218.

15. Mariano F, Morselli M, Bergamo D, Hollo Z, Scella S, Maio M, Tetta C, Dellavalle A, Stella M, Triolo G: Blood and ultrafiltrate dosage of citrate as a useful and routine tool during continuous venovenous haemodiafiltration in septic shock patients. Nephrol Dial Transplant 2011, 26:3882-3888.

16. Mehta RL, McDonald BR, Aguilar MM, Ward DM: Regional citrate anticoagulation for continuous arteriovenous hemodialysis in critically ill patients. Kidney Int 1990, 38:976-981.

17. Kutsogiannis DJ, Gibney RT, Stollery D, Gao J: Regional citrate versus systemic heparin anticoagulation for continuous renal replacement in critically ill patients. Kidney Int 2005, 67:2361-2367.

18. Tolwani AJ, Prendergast MB, Speer RR, Stofan BS, Wille KM: A practical citrate anticoagulation continuous venovenous hemodiafiltration protocol for metabolic control and high solute clearance. Clin J Am Soc Nephrol 2006, 1:79-87.

19. Morgera S, Scholle C, Melzer C, Slowinski T, Liefeld L, Baumann G, Peters H, Neumayer $\mathrm{HH}$ : A simple, safe and effective citrate anticoagulation protocol for the genius dialysis system in acute renal failure. Nephron Clin Pract 2004, 98:c35-c40.

20. Monchi M, Berghmans D, Ledoux D, Canivet JL, Dubois B, Damas P: Citrate vs. heparin for anticoagulation in continuous venovenous hemofiltration: a prospective randomized study. Intensive Care Med 2004, 30:260-265.

21. Tobe SW, Aujla P, Walele AA, Oliver MJ, Naimark DM, Perkins NJ, Beardsall M: A novel regional citrate anticoagulation protocol for CRRT using only commercially available solutions. J Crit Care 2003, 18:121-129.

22. Swartz R, Pasko D, O'Toole J, Starmann B: Improving the delivery of continuous renal replacement therapy using regional citrate anticoagulation. Clin Nephrol 2004, 61:134-143.

23. Shum HP, Chan KC, Yan WW: Regional citrate anticoagulation in predilution continuous venovenous hemofiltration using prismocitrate $10 / 2$ solution. Ther Apher Dial 2012, 16:81-86.

24. Palsson R, Niles JL: Regional citrate anticoagulation in continuous venovenous hemofiltration in critically ill patients with a high risk of bleeding. Kidney Int 1999, 55:1991-1997.

25. Dorval M, Madore F, Courteau S, Leblanc M: A novel citrate anticoagulation regimen for continuous venovenous hemodiafiltration. Intensive Care Med 2003, 29:1186-1189.

26. Gabutti L, Marone C, Colucci G, Duchini F, Schonholzer C: Citrate anticoagulation in continuous venovenous hemodiafiltration: a metabolic challenge. Intensive Care Med 2002, 28:1419-1425

27. Thoenen M, Schmid ER, Binswanger U, Schuepbach R, Aerne D, Schmidlin D Regional citrate anticoagulation using a citrate-based substitution solution for continuous venovenous hemofiltration in cardiac surgery patients. Wien Klin Wochenschr 2002, 114:108-114.

28. Egi M, Naka T, Bellomo R, Langenberg CC, Li W, Fealy N, Baldwin I: The acidbase effect of changing citrate solution for regional anticoagulation during continuous veno-venous hemofiltration. Int J Artif Organs 2008, 31:228-236.

29. Aman J, Nurmohamed SA, Vervloet MG, Groeneveld AB: Metabolic effects of citrate- vs bicarbonate-based substitution fluid in continuous venovenous hemofiltration: a prospective sequential cohort study. J Crit Care 2010, 25:120-127.

30. Morgan TJ: The Stewart approach - one clinician's perspective. Clin Biochem Rev 2009, 30:41-54

31. Palsson R, Laliberte KA, Niles JL: Choice of replacement solution and anticoagulant in continuous venovenous hemofiltration. Clin Nephrol 2006, 65:34-42.

32. Zhang Z, Hongying N: Efficacy and safety of regional citrate anticoagulation in critically ill patients undergoing continuous renal replacement therapy. Intensive Care Med 2012, 38:20-28.

33. Fealy N, Baldwin I, Johnstone M, Egi M, Bellomo R: A pilot randomized controlled crossover study comparing regional heparinization to regional citrate anticoagulation for continuous venovenous hemofiltration. Int Artif Organs 2007, 30:301-307.

34. Wu MY, Hsu YH, Bai CH, Lin YF, Wu CH, Tam KW: Regional citrate versus heparin anticoagulation for continuous renal replacement therapy: a meta-analysis of randomized controlled trials. Am J Kidney Dis 2012, 59:810-818.

35. Hetzel GR, Schmitz M, Wissing H, Ries W, Schon G, Heering PJ, Isgro F, Kribben A, Himmele R, Grabensee B, Rump LC: Regional citrate versus systemic heparin for anticoagulation on critically ill patients on continuous venovenous haemofiltration: a prospective randomized multicentre trial. Nephrol Dial Transplant 2010, 26:232-239.

36. Chatham JC, Des RC, Forder JR: Evidence of separate pathways for lactate uptake and release by the perfused rat heart. Am J Physiol Endocrinol Metab 2001, 281:E794-E802

37. Mazer CD, Stanley WC, Hickey RF, Neese RA, Cason BA, Demas KA, Wisneski JA, Gertz EW: Myocardial metabolism during hypoxia: maintained lactate oxidation during increased glycolysis. Metabolism 1990, 39:913-918.

38. Kline JA, Thornton LR, Lopaschuk GD, Barbee RW, Watts JA: Lactate improves cardiac efficiency after hemorrhagic shock. Shock 2000, 14:215-221.

39. Levy B, Mansart A, Montemont C, Gibot S, Mallie JP, Regnault V, Lecompte T, Lacolley P: Myocardial lactate deprivation is associated with decreased cardiovascular performance, decreased myocardial energetics, and early death in endotoxic shock. Intensive Care Med 2007, 33:495-502.

40. Leverve XM, Boon C, Hakim T, Anwar M, Siregar E, Mustafa I: Half-molar sodium-lactate solution has a beneficial effect in patients after coronary artery bypass grafting. Intensive Care Med 2008, 34:1796-1803.

41. Owen OE, Kalhan SC, Hanson RW: The key role of anaplerosis and cataplerosis for citric acid cycle function. J Biol Chem 2002, 277:30409-30412.

42. Weinberg JM, Venkatachalam MA, Roeser NF, Nissim I: Mitochondrial dysfunction during hypoxia/reoxygenation and its correction by anaerobic metabolism of citric acid cycle intermediates. Proc Natl Acad Sci USA 2000, 97:2826-2831.

43. Vary TC, Hazen S: Sepsis alters pyruvate dehydrogenase kinase activity in skeletal muscle. Mol Cell Biochem 1999, 198:113-118.

44. Leverve XM, Mustafa I: Lactate: A key metabolite in the intercellular metabolic interplay. Crit Care 2002, 6:284-285.

45. Balik M, Zakharchenko M, Leden F, Otahal M, Hruby J, Polak F, Rusinova K, Zdenek S, Tokarik M, Jabor A, Oudemans-van Straaten HM: Bioenergetic gain of citrate anticoagulated continuous hemodiafiltration - a comparison between two citrate modalities and unfractionated heparin. J Crit Care 2012 [Epub ahead of print].

46. Andersson T, Dahlgren C, Pozzan T, Stendahl O, Lew PD: Characterization of fMet-Leu-Phe receptor-mediated $\mathrm{Ca} 2+$ influx across the plasma membrane of human neutrophils. Mol Pharmacol 1986, 30:437-443.

47. Dhondt A, Vanholder R, Tielemans C, Glorieux G, Waterloos MA, De SR, Lameire N: Effect of regional citrate anticoagulation on leukopenia, complement activation, and expression of leukocyte surface molecules during hemodialysis with unmodified cellulose membranes. Nephron 2000, 85:334-342.

48. Berridge MJ, Bootman MD, Roderick HL: Calcium signalling: dynamics, homeostasis and remodelling. Nat Rev Mol Cell Biol 2003, 4:517-529.

49. Tintinger GR, Steel HC, Theron AJ, Anderson R: Pharmacological control of neutrophil-mediated inflammation: Strategies targeting calcium handling by activated polymorphonuclear leukocytes. Drug Des Devel Ther 2009, 2:95-104.

50. Bohler J, Schollmeyer P, Dressel B, Dobos G, Horl WH: Reduction of granulocyte activation during hemodialysis with regional citrate anticoagulation: dissociation of complement activation and neutropenia from neutrophil degranulation. J Am Soc Nephrol 1996, 7:234-241.

51. Bos JC, Grooteman MP, van Houte AJ, Schoorl M, van Limbeek J, Nube MJ: Low polymorphonuclear cell degranulation during citrate anticoagulation: a comparison between citrate and heparin dialysis. Nephrol Dial Transplant 1997, 12:1387-1393.

52. Gabutti L, Ferrari N, Mombelli G, Keller F, Marone C: The favorable effect of regional citrate anticoagulation on interleukin-1beta release is dissociated from both coagulation and complement activation. J Nephrol 2004, 17:819-825.

53. Gritters M, Grooteman MP, Schoorl M, Schoorl M, Bartels PC, Scheffer PG, Teerlink T, Schalkwijk CG, Spreeuwenberg M, Nube MJ: Citrate anticoagulation abolishes degranulation of polymorphonuclear cells and 
platelets and reduces oxidative stress during haemodialysis. Nephrol Dial Transplant 2006, 21:153-159.

54. Ding F, Song JH, Jung JY, Lou L, Wang M, Charles L, Westover A, Smith PL, Pino CJ, Buffington DA, Humes HD: A biomimetic membrane device that modulates the excessive inflammatory response to sepsis. PLoS One 2011, 6:e18584.

55. Polanska K, Opatrny K Jr, Rokyta R Jr, Krouzecky A, Vit L, Kasal E: Effect of regional citrate anticoagulation on thrombogenicity and biocompatibility during CVVHDF. Ren Fail 2006, 28:107-118.

56. Tyrrell DJ, Horne AP, Holme KR, Preuss JM, Page CP: Heparin in inflammation: potential therapeutic applications beyond anticoagulation. Adv Pharmacol 1999, 46:151-208

57. Li Y, Sun JF, Cui X, Mani H, Danner RL, Li X, Su JW, Fitz Y, Eichacker PQ: The effect of heparin administration in animal models of sepsis: a prospective study in Escherichia coli-challenged mice and a systematic review and metaregression analysis of published studies. Crit Care Med 2011, 39:1104-1112.

58. Hochart H, Jenkins PV, Preston RJ, Smith OP, White B, O'Donnell J: Concentration-dependent roles for heparin in modifying lipopolysaccharide-induced activation of mononuclear cells in whole blood. Thromb Haemost 2008, 99:570-575.

59. Li X, Zheng Z, Li X, Ma X: Unfractionated heparin inhibits lipopolysaccharide-induced inflammatory response through blocking p38 MAPK and NF-kappaB activation on endothelial cell. Cytokine 2012, 60:114-121.

60. Zarychanski R, Doucette S, Fergusson D, Roberts D, Houston DS, Sharma S, Gulati H, Kumar A: Early intravenous unfractionated heparin and mortality in septic shock. Crit Care Med 2008, 36:2973-2979.

61. Ding R, Zhao D, Guo R, Zhang Z, Ma X: Treatment with unfractionated heparin attenuates coagulation and inflammation in endotoxemic mice. Thromb Res 2011, 128:e160-e165.

62. Jaimes F, De La Rosa G, Morales C, Fortich F, Arango C, Aguirre D, Munoz A: Unfractioned heparin for treatment of sepsis: A randomized clinical trial (The HETRASE Study). Crit Care Med 2009, 37:1 185-1196.

63. Gebska MA, Titley I, Paterson HF, Morilla RM, Davies DC, Gruszka-Westwood AM, Kakkar VV, Eccles S, Scully MF: High-affinity binding sites for heparin generated on leukocytes during apoptosis arise from nuclear structures segregated during cell death. Blood 2002, 99:2221-2227.

64. Gritters M, Borgdorff P, Grooteman MP, Schoorl M, Schoorl M, Bartels PC, Tangelder GJ, Nube MJ: Platelet activation in clinical haemodialysis: LMWH as a major contributor to bio-incompatibility? Nephrol Dial Transplant 2008, 23:2911-2917.

65. Borawski J: Myeloperoxidase as a marker of hemodialysis biocompatibility and oxidative stress: the underestimated modifying effects of heparin. Am $J$ Kidney Dis 2006, 47:37-41

66. Hoffmann JN, Vollmar B, Laschke MW, Inthorn D, Kaneider NC, Dunzendorfer S, Wiedermann CJ, Romisch J, Schildberg FW, Menger MD: Adverse effect of heparin on antithrombin action during endotoxemia: microhemodynamic and cellular mechanisms. Thromb Haemost 2002, 88:242-252.

67. Heinzelmann M, Bosshart H: Heparin binds to lipopolysaccharide (LPS)binding protein, facilitates the transfer of LPS to CD14, and enhances LPS-induced activation of peripheral blood monocytes. J Immuno/ 2005, 174:2280-2287.

68. Jordan RE, Nelson RM, Kilpatrick J, Newgren JO, Esmon PC, Fournel MA: Antithrombin inactivation by neutrophil elastase requires heparin. Am J Med 1989, 87:195-22S

69. Bakker AJ, Boerma EC, Keidel H, Kingma P, van der Voort PH: Detection of citrate overdose in critically ill patients on citrate-anticoagulated venovenous haemofiltration: use of ionised and total/ionised calcium. Clin
Chem Lab Med 2006, 44:962-966

70. Hetzel GR, Taskaya G, Sucker C, Hennersdorf M, Grabensee B, Schmitz M: Citrate plasma levels in patients under regional anticoagulation in continuous venovenous hemofiltration. Am J Kidney Dis 2006, 48:806-811.

71. Link A, Klingele M, Speer T, Rbah R, Poss J, Lerner-Graber A, Fliser D, Bohm M: Total-to-ionized calcium ratio predicts mortality in continuous renal replacement therapy with citrate anticoagulation in critically ill patients. Crit Care 2012, 16:R97.

72. Muller B, Becker KL, Kranzlin M, Schachinger H, Huber PR, Nylen ES, Snider RH, White JC, Schmidt-Gayk H, Zimmerli W, Ritz R: Disordered calcium homeostasis of sepsis: association with calcitonin precursors. Eur $\mathrm{Clin}$ Invest 2000, 30:823-831.

73. Zaloga GP, Sager A, Black KW, Prielipp R: Low dose calcium administration increases mortality during septic peritonitis in rats. Circ Shock 1992, 37:226-229.

74. Kramer L, Bauer E, Joukhadar C, Strobl W, Gendo A, Madl C, Gangl A: Citrate pharmacokinetics and metabolism in cirrhotic and noncirrhotic critically ill patients. Crit Care Med 2003, 31:2450-2455.

75. Apsner R, Schwarzenhofer M, Derfler K, Zauner C, Ratheiser K, Kranz A: Impairment of citrate metabolism in acute hepatic failure. Wien Klin Wochenschr 1997, 109:123-127.

76. Faybik P, Hetz H, Mitterer G, Krenn CG, Schiefer J, Funk GC, Bacher A: Regional citrate anticoagulation in patients with liver failure supported by a molecular adsorbent recirculating system. Crit Care Med 2011, 39:273-279.

77. Meijers B, Laleman W, Vermeersch P, Nevens F, Wilmer A, Evenepoel P: A prospective randomized open-label crossover trial of regional citrate anticoagulation vs. anticoagulation free liver dialysis by the Molecular Adsorbents Recirculating System. Crit Care 2012, 16:R20

78. Slowinski T, Morgera S, Joannidis M, Kindgen-Milles D: Multicenter prospective observational study on safety and efficacy of regional citrate anticoagulation in CVVHD in the presence of liver failure: the Liver Citrate Anticoagulation Treshold Study (L-CAT). Crit Care 2011, 15(Suppl 1):P127.

79. Wang PL, Meyer MM, Orloff SL, Anderson S: Bone resorption and "relative" immobilization hypercalcemia with prolonged continuous renal replacement therapy and citrate anticoagulation. Am J Kidney Dis 2004, 44:1110-1114

80. van der Voort PH, Postma SR, Kingma WP, Boerma EC, de Heide LJ, Bakker AJ: An observational study on the effects of nadroparin-based and citratebased continuous venovenous hemofiltration on calcium metabolism. Blood Purif 2007, 25:267-273.

81. Brain M, Parkes S, Fowler P, Robertson I, Brown A: Calcium flux in continuous venovenous haemodiafiltration with heparin and citrate anticoagulation. Crit Care Resusc 2011, 13:72-81.

82. Thijssen S, Kruse A, Raimann J, Bhalani V, Levin NW, Kotanko P: A mathematical model of regional citrate anticoagulation in hemodialysis. Blood Purif 2010, 29:197-203.

83. Szamosfalvi B, Frinak S, Yee J: Automated regional citrate anticoagulation: technological barriers and possible solutions. Blood Purif 2010, 29:204-209.

84. Brandl M, Strobl K, Hartmann J, Kellner K, Posnicek T, Falkenhagen D: A target-orientated algorithm for regional citrate-calcium anticoagulation in extracorporeal therapies. Blood Purif 2012, 33:7-20.

85. Kidney Disease: Improving Global Outcomes (KDIGO) [http://www.kdigo.org/]

doi:10.1186/cc11645

Cite this article as: Oudemans-van Straaten HM, Ostermann M: Bench-tobedside review: Citrate for continuous renal replacement therapy, from science to practice. Critical Care 2012, 16:249. 